\title{
TECNOLOGIAS DA INFORMAÇÃO E DA COMUNICAÇÃO PARA EMPODERAMENTO: REFLEXÕES PARA A EDUCAÇÃO DESTE INÍCIO DE SÉCULO
}

\author{
INFORMACIÓN Y LA COMUNICACIÓN PARA EMPODERAMIENTO: \\ REFLEXIONES PARA LA FORMACIÓN DE ESTE NUEVO SIGLO
}

INFORMATION AND COMMUNICATION TECHNOLOGIES FOR EMPOWERMENT: REFLECTIONS FOR EARLY 20TH CENTURY EDUCATION

\author{
Márcia Lopes REIS ${ }^{1}$
}

GAIRIN, Joaquín (org.). Aprendizaje situado y aprendizaje conectado: implicaciones para el trabajo. Madrid: Wolters Kluwer España, 2016.

Em termos teóricos e práticos, parece oportuna a publicação dessa obra em meados da segunda década do século XXI e sua (co)incidência com a morte de Alvin Tofler (1928- 2016). Esse autor ficou conhecido por suas análises - não acadêmicas sobre o excesso de informação e os modos de redução da jornada de trabalho com a utilização da tecnologia, de modo efetivo. Nesse 'novo' contexto, descrito por ele ao longo de suas obras amplamente acessíveis como best-sellers, "o analfabeto não seria quem não sabe ler nem escrever, mas os que não têm capacidade de aprender e reaprender". Chama a atenção que algo amplamente propalado sem a rapidez das redes sociais dos dias de hoje, tenha ultrapassado o final do século passado e chegado aos nossos dias e se tornado objeto de análises científicas e tema de intercâmbios de vivências e experiências. Desse modo, pode ser apresentada essa obra necessária aos distintos interlocutores: gestores de distintas organizações, gestores das práticas educativas, professores dos distintos níveis de ensino e aprendizagem, bem como estudiosos do tema sobre os impactos das tecnologias da informação no cotidiano das instituições e organizações como 'entes aprendentes'

Distribuída em 22 capítulos que estão agrupados em sete seções (Apartados), o primeiro conjunto de artigos aborda os aspectos gerais sobre a aprendizagem nas organizações. A partir de um texto introdutório do editor da obra, Joaquín Gairín, professor da Universitat Autònoma de Barcelona e coordenador do EDO (Equipo de

\footnotetext{
${ }^{1}$ Professora da UNESP/FC - campus Bauru, doutora em Sociologia UnB, mestre em Educação UnB, especialista em Supervisão e Curriculo (UFMT) e pedagoga. Professora colaboradora do Programa de Pós-Graduação em Sociologia da UNICAMP. Email: marciareis@ @c.unesp.br
} 
Desarrollo Organizacional) e líder da RedAGE (Red de Apoyo a la Gestión Educativa) ficam evidentes os fatores que explicam o tema das mudanças decorrentes da busca da aquisição do conhecimento como um processo pessoal ou organizacional em que novos contextos demandam aprendizados distintos. Assim, o conceito de aprendizagem 'situada' evidenciaria a impossibilidade de separação desse processo do seu contexto. Aparentemente, nada parece novo, pois a perspectiva de que o conhecimento é contextualizado, bem como a percepção de que os conteúdos (escolares e não escolares) não podem ser desvinculados da experiência direta da situação figura como consenso há algum tempo, desde os gregos, pensadores medievais até os pensadores mais recentes níveis (FREIRE, 1975; GIROUX, 1992; YOUNG, 1971;, dentre outros).

No entanto, as relações entre a aprendizagem situada e a aprendizagem conectada resultariam na configuração de novos processos nos quais o trabalho compartilhado, e em rede, incrementaria o arcabouço teórico e experiencial. Assim, inicialmente, para o organizador da obra, fica evidente algo inovador: a tradicional definição das TIC ('tecnologias da informação e da comunicação') tendem a se configurar em TAC ('tecnologias de aprendizagem e conhecimento') para alcançarem a condição de TEP ('tecnologias de empoderamento e participação'). Seria a vinculação desses conceitos à realidade do trabalho e, mais especificamente, à prática reflexiva desses sujeitos em seus lugares de atuação que tornarão possível um desenvolvimento da organização que aprende, inclusive as instituições escolares.

Pode-se notar que o centro da mudança estaria na transformação do contexto de trabalho em uma experiência de formação que parece rever as clássicas teorias de mudança nas instituições. Nessas análises, os processos de querer (atitudes positivas no sentido de melhorar a atividade profissional), saber (conhecimentos sobre as novas formas de fazer e atuar), poder (possibilidade de implementar as aprendizagens realizadas) e incentivos (reconhecimento dos novos esforços para implementação das mudanças) transformariam o ambiente de trabalho em um contexto de formação.. Para isso, as teorias sistêmicas, bem como da complexidade auxiliam na compreensão da multiplicidade de fatores que interferem nessa realidade e, por sua vez, as abordagens ecológicas dão conta das diferenças de contextos.

Interessante que as apresentações realizadas durante o Congresso EDO 2016 cumprem a função de focalizar as formas de aprendizagem nas organizações com ênfase naquelas relacionadas ao ambiente de trabalho agregando, desse modo, distintas abordagens dos congressos anteriores desde 2010, sendo realizado a cada dois anos. Assim, se destacam a releitura da aprendizagem mimética de Stephen Billett 
(Universidade de Griffith - Austrália) atribuindo novos elementos à observação e imitação dos expertos e experientes profissionais no ambiente de trabalho. Para tanto, o ato mecânico é superado para se tornar em processos interpessoais de aprendizagens.

No sentido das práticas reflexivas, outro seminário apresentado por Harol Jarche propõe práticas de gestão pessoal do conhecimento (PKM, do inglês, Personal Knowledge Manager) que acentua o caráter pessoal do processo de dar sentido à informação, ás ideias e ás observações realizadas. A ênfase estaria em aproveitar as possiblidades de uma aprendizagem continua, compartilhando as dimensões individual, organzacional e das redes. Esse autor define esse processo como uma aprendizagem social e as técnicas de PKM podem auxiliar nesse processo.

A amplitude e a liquidez da informação, a complexidade dos cenários e a importância do conhecimento constituem a apresentação de Julio Cabero (Universidad de Sevilla) ao apresentar o histórico que nos levou à situação atual. Nesse contexto, o trabalho co-laborativo será o diferencial às pessoas e organizações desse tempo. Assim, terminaria a primeira seção que dá início aos sentidos da Inovação na Formação como foco do Apartado B que tem nas novas formas de aprendizagem temas como a ideia da formação de um paradigma de aprendizagem, os bancos de conhecimentos, a dinamização dos conteúdos a partir de um caso prático de tutela de conteúdos organizacionais, os programa de intercâmbios de experiências mediadas por períodos de formação para o pessoal a serviço das administrações públicas da região de Múrcia, a gestão da formação à gestão do conhecimento e, ao final, o ecossistema de aprendizagem na administração da Generalitat de Catalunha no começo de suas mudanças.

Ainda no Apartado B, os capítulos seguintes estão agrupados em torno das novas experiências de aprendizagem situados nas organizações. Desde as e-comunidades passando pelas áreas de direitos sociais do Ayuntamiento de Barcelona, os programas NEXUS24 da Universitat Politécnica de Catalunya, o Webinar e o Programa CCCB 1 constituem o conjunto de relatos apresentados. Na sequência, a ênfase é dada às experiências aplicadas à transformação da formação tradicional no âmbito das organizações públicas. O setor público é apresentado em distintos momentos de mudança que incluem um relato interessante de uma experiência chamada de 'wikicontratação'. Chamam a atenção, pois até mesmo processo tão complexo como o ingresso na carreira do serviço público pode ser ambiente para essas práticas inovadoras. No capítulo final desse Apartado, os MOOC (Massive Open Online Courses) constituem o foco dessas experiências a partir dos cursos on-line 
implementados na Internet a partir dos princípios de educação em massa e aberta. Seria interessante para um organismo público elaborar MOOC? Somente as universidades podem elaborar MOOC? Essa ferramenta pode ser um bom produto para a formação aberta de um organismo público? Essas perguntas instigam essas reflexões que tratam dos prós e contras com a coordenação de Sylvia Alonso Codina.

O Apartado $\mathrm{C}$ tem como foco a avaliação e as reflexões coletivas para a melhoria dos processos de aprendizagem situada e conectada. Partindo do conceito de avaliação das comunidades de prática profissional, o contexto do Big Data e as abordagens situadas e sua relação com os aprendizados coletivos esse conjunto de artigos coordenado por Maria Inés Vazquez aborda a importância da liderança educativa sustentável nos processos de mudança, a construção de caminhos para um trabalho colaborativo em um centro de educação primária, a gestão da imagem institucional de um centro educativo, a consolidação da identidade institucional como um desafio para a gestão que finalizam com uma abordagem sobre a construção de um clima institucional favorável às mudanças institucionais constantes.

A transformação da educação superior é o foco do Apartado D que tem início com a abordagem sobre a produção e a gestão do conhecimento em uma instituição de educação superior coordenado por Sebastián Sánchez Diaz, as análises do Observatório Nacional da Fundação DUOC - entidade de ensino superior técnico profissional (ESTP) fundada pela Universidad Católica de Chile há mais de 45 anos. Atualmente, supera os 90 mil alunos, com mais de 4 mil professores e cerca de 2 mil funcionários administrativos. Distribuída em 3 regiões do Chile sendo região metropolitana com 13 sedes, Biobio e Valparaíso com 2 sedes cada uma o que indica a magnitude da mudança analisada. Atualmente, responsável por 7\% das matrículas totais do país, essa instituição promoveu transformações no sentido da aprendizagem situada e conectada descritas em três iniciativas. A primeira foi a criação de um espaço de experiência de um observatório da educação superior técnica e profissional. Trata-se de uma plataforma permanente e atualizada que integra informação parcialmente dispersa. Após sistematizá-las, apresenta análises e opiniões quantitativas, gera e fomenta, de maneira periódica, os distintos usuários no campo da educação profissional técnica profissional. Decorrente da constituição desse observatório, como segunda iniciativa, a Fundação DUOC, implementou um modelo de gestão de conhecimento que abrange metodologias, processos, papéis, recursos e mecanismos de governança. Por fim, dada a necessidade de impulsionar e organizar o desenvolvimento da inovação, os autores apresentam a criação e o funcionamento do processo definido como 'Proyecta Duoc' 
cujo sentido é a consolidação da capacidade de inovação institucional. Assim, se encerra o conjunto de publicações impressas dessa obra que se completa com o CD ROM que contém outros três apartados.

O foco do Apartado E são as aprendizagens situadas em diferentes níveis educativos que inclui os espaços não-formais de formação. No caso do Apartado $\mathrm{F}$, outros cinco capítulos são dedicados à gestão do conhecimento e inovação em contextos formativos igualmente em diferentes níveis. No entanto, a abrangência dessa obra abarca, no Apartado G, o conjunto dos coletivos vulneráveis e a gestão do conhecimento que inclui no capítulo 21 as narrativas e análises das intervenções socioeducativas em contextos vulneráveis no sul da Europa. A metodologia APRA (Acceso, Permanencia e Rendimento Acadêmico) é apresentada no último capítulo pela pesquisadora Guadalupe Palmeros y Avila e introduzido por Adoración Barrales, ambas participaram do Proyecto Accedes (2012 - 2014) que visou desenvolver, desenhar, aplicar e avaliar planos de melhoria dos processos de acesso e permanência na educação superior, sobretudo, das universidades da América Latina, valendo-se de ferramentas de gestão de conhecimento.

Nesse sentido, a importância dessa obra remete às possibilidades de efetivação de um projeto comum às organizações quando realizam a aprendizagem situada e conectada: a formação qualitativa dos sujeitos desse tempo.

No caso das instituições educativas, o processo de transformação das TIC em TEP reforça a importância dessa obra, pois aprofunda e detalha experiências e análises no cumprimento da função social das tecnologias em relação aos coletivos vulneráveis que orientou as atividades coordenadas pelo próprio prof. Joaquin Gairin na liderança do Proyecto Accedes :ao "promover a permanência na universidade e seu maior êxito acadêmico" (GAIRIN, 2014,p. 173).

\section{Como referenciar esta resenha:}

REIS, Márcia Lopes. Tecnologias da informação e da comunicação para empoderamento: reflexões para a educação deste início de século. Revista IberoAmericana de Estudos em Educação, Araraquara, v. 11, n. 4, p. 2245-2249, 2016. Disponível em: 〈http://dx.doi.org/10.21723/riaee.v11.n4.9163〉. E-ISSN: 1982-5587.

Submetido em: outubro/2016

Aprovação final em: dezembro/2016 